\title{
Cuba, los intelectuales y la nueva izquierda
}

\section{Memorias y miradas de Rafael Rojas}

Rafael Rojas es un filósofo e historiador cubano con una extensa trayectoria en México. Por muchos años trabajó en la División de Historia del Centro de Investigación y Docencia Económica (CIDE) y en la actualidad integra la planta académica del Colegio de México, donde dirige la revista Historia Mexicana. Es autor de numerosos libros, trabajos académicos y notas periodísticas que discuten la actualidad de Cuba desde diversas aristas de su historia política, cultural e intelectual. Rojas proviene de una familia con protagonismo en la política oficial cubana, pero su trayectoria tomó un rumbo diferente. En los años ochenta formó parte de los movimientos culturales juveniles que acompañaron críticamente al proyecto socialista de la isla y en los noventa integró la diáspora de artistas, escritores, académicos, cineastas y teatreros que exigía un proceso de reformas políticas y culturales como el que tenía lugar en el bloque soviético tras la caída del Muro de Berlín. Esta disidencia y migración, muy distinta al anticomunismo y anticastrismo radicado en Miami, se desperdigó por diversas capitales del mundo, como New York, Madrid, Barcelona y Ciudad de México.

En esta entrevista, indagamos con Rojas en su trayectoria político intelectual para entender las discusiones más relevantes que aborda en su extensa obra. Además, examinamos dos temáticas centrales de sus investigaciones actuales que hacen al campo de la historia reciente latinoamericana: la relación entre política e intelectuales y los desafíos que suscitan los usos analíticos de la categoría nueva izquierda.

\section{Primera parte: trayectoria político} intelectual de un cubano de la diáspora

-Podemos comenzar por tu libro Tumbas sin sosiego. Revolución, disidencia y exilio del intelectual cubano (2006) para

* Becario del Programa de Becas Postdoctorales de la Universidad Nacional Autónoma de México, en el Instituto de Investigaciones Sociales, bajo la asesoría del Dr. Sergio Zermeño y García Granados. Doctor en Historia por la Facultad de Humanidades y Ciencias de la Educación de la Universidad Nacional de La Plata. https://orcid.org/0000-0001-65657319. Correo: nicolasdip88@gmail.com. proponer una serie de preguntas que permitan reconstruir tu trayectoria intelectual. En el trabajo se sostiene que cualquier acercamiento a la historia cultural contemporánea cubana debe enfrentarse al cambio producido desde el triunfo revolucionario de 1959, ya que este proceso quebró el campo intelectual de la isla en actitudes de adhesión y rechazo tributarias de la Guerra Fría. Lo interesante es que a la vez se afirma que una complejización teórica sobre los dilemas del intelectual público cubano de 1959 a la fecha, tiene pocas posibilidades epistemológicas si aspira a una sublimación o represión del problema. Frente a esto se sugiere que, en vez de una omisión de la disyuntiva, deben utilizarse políticas de la memoria y desplazamientos conceptuales que permitan representar de manera equitativa el comportamiento de los actores involucrados, pero sin desconocer la polarización de la comunidad cubana desde el nivel familiar hasta el nacional. En este punto, para analizar tu propia trayectoria intelectual desde la memoria, podemos iniciar con una serie de preguntas para entender cuáles son los momentos de tu vida en la isla y fuera de ella que son relevantes en la formación de tus preocupaciones actuales sobre política e intelectuales. En relación con tu primera etapa de formación, ¿cómo fue tu ambiente familiar dentro de Cuba y tus primeros acercamientos a la filosofía, la historia y la política?

- Tuve una infancia y adolescencia muy parecida a la de quienes vivimos en Cuba en el período socialista de mayor identificación con la Unión Soviética, en los años setenta y ochenta. Cursé la secundaria y el pre universitario en una escuela emblemática de ese sistema educativo que se llamaba Escuela Vocacional Vladímir llich Lenin. Creo que todavía existe, aunque ahora es un pre universitario de ciencias exactas. En mi época era un internado desde la secundaria, desde que tenías unos once o doce años, hasta que terminabas el bachillerato. Luego de cursar toda la secundaria y el pre universitario en esa escuela, opté por una carrera en la Unión Soviética. Ahí pasé unos dos años estudiando algo que se Llamaba "Cibernética Económica", pero en realidad era economía política marxista leninista. Luego regresé a La Habana y cursé la carrera de filosofía entre 1985 y 1990. Mi título 
universitario dice "Licenciado en Filosofía Marxista Leninista". Era el típico programa de estudios que predominaba en la Unión Soviética y en los países del socialismo real hasta la caída del Muro de Berlín.

Esa fue mi primera formación y mi familia era una familia universitaria. Mi padre fue Rector de la Universidad de La Habana por muchos años y mi madre era profesora de biología en la misma institución. Mi padre y mi abuelo fueron médicos. Pero en el caso de mi padre, un médico que se desplazó a las labores administrativas dentro de la Universidad. El período que me tocó en la Universidad, entre 1985 y 1990, estuvo signado por la crisis final del socialismo real. Entonces toda mi generación experimentó desde La Habana los procesos de cambio que se vivían en la Unión Soviética y Europa del Este. Yo mismo había vivido en la Unión Soviética entre el año 1983 y 1985 y luego en 1990 hice una estancia final de investigación en Moscú, unos meses antes de graduarme. Mi tesis de licenciatura nunca se editó como libro, pero se publicó un capítulo muy largo en una revista llamada Contracorriente, a fines de los años ochenta. Se titulaba originalmente "Marx y la historia" e intentaba una reinterpretación del materialismo histórico, a la luz de las lecturas del posestructuralismo francés y de la filosofía posmoderna, que muchos de nosotros seguíamos en aquellos años en La Habana.

Es importante colocarnos en los debates de entonces y en las formas un tanto precarias en que los estudiantes de filosofía en La Habana nos acercábamos a las corrientes posestructuralistas, críticas o posmodernas. Nuestro programa de estudios estaba muy enfocado en la filosofía soviética. A mí me tocó estudiar el materialismo dialéctico siguiendo las tesis de Évald Iliénkov, un filósofo soviético neohegeliano que defendía la lógica dialéctica como núcleo de esa concepción. El materialismo histórico también se estudiaba siguiendo las tesis de otro filósofo soviético, Zaid Orudzhev. Éste tenía una orientación no tan dogmática como la de los "manualistas", quienes basaban su marxismo en la determinación de la "superestructura" por la "base" y en la teoría de la sucesión de formaciones económicas y sociales. Por un lado, estaba la metateoría soviética de los manuales de Konstantinov y Afanasiev, pero a la vez había un grupo de filósofos académicos un poco más serios, como lliénkov y Orudzhev. Ellos fueron referentes centrales en nuestra formación.

Por otra parte, durante el proceso de la licenciatura y al calor de los cambios que tenían lugar en Europa del Este, nos fuimos acercando a otras corrientes. En mi caso fue fundamental entrar en contacto con Pensamiento Crítico, una revista que se editó en Cuba bajo la dirección de Fernando Martínez Heredia y en cuyo comité editorial había algunos intelectuales que fueron aislados de la Universidad en 1971, cuando comenzó la sovietización de la isla. Eran figuras muy seguidas por los estudiantes de filosofía de mi generación por de diversas razones. Uno de ellos, Jesús Díaz, novelista, filósofo y director de cine, fue muy popular entre nosotros. En 1986 se había publicado su novela Las iniciales de la tierra, que narraba la historia de un joven cubano que cae en desgracia a partir del momento en que redacta un "cuéntame tu vida", una especie de autobiografía que le pedían a los militantes para ascender en los escalafones dentro de la Unión de Jóvenes Comunistas. Esa novela de Díaz fue muy importante para nosotros, al igual que sus películas.

- Y esos jóvenes estudiantes de filosofía durante su vida cotidiana en la isla y en la universidad a fines de los ochenta ¿cómo entraban en contacto con esos espacios y qué tipo de lecturas encontraban en ellos?

- La revista Pensamiento Crítico estaba completa en la biblioteca de la Facultad de Filosofía e Historia. Sus principales representantes vivían en la isla y estaban ubicados en otros centros, pero no intervenían directamente en la Universidad. Nosotros, los estudiantes, buscamos la manera de acercarnos a ellos. Te ponía el ejemplo de Jesús Díaz porque recuerdo que los estudiantes, no los profesores, lo invitamos por primera vez a la Facultad desde que cerraron la revista en 1971. También nos acercamos a Fernando Martínez Heredia, a Aurelio Alonso y a Juan Valdés Paz. Todos ellos eran académicos y científicos sociales de Pensamiento Crítico, pero estaban afiliados al Centro de Estudios sobre América (CEA). Para mí lo fundamental de entrar en contacto con esa revista fue el acceso a la filosofía más contemporánea de la izquierda occidental. A través de la publicación pude conocer algo de la teoría crítica alemana, especialmente de Marcuse y Adorno, traducidos en Pensamiento Crítico. También pude vincularme con el estructuralismo y el posestructuralismo. Hice un estudio reciente sobre Pensamiento Crítico y puedo asegurar que la figura filosófica central en la revista fue Louis Althusser. Para mí, y creo que para buena parte de mi generación, fue muy importante la obra de este marxista francés. A través de Althusser acabamos leyendo naturalmente a Foucault, a Derrida, a Lyotard, a los filósofos del posestructuralismo francés. Pensamiento Crítico fue también la puerta de acceso a una corriente que para mí sigue siendo fundamental en la actualidad, la del marxismo social británico, con obras como las de E. P. Thompson y Eric Hobsbawm. Esos autores no circulaban en Cuba en los años ochenta, pero Pensamiento Crítico los había traducido. También tradujeron a Robin Blackburn, Ralph Miliband y Perry Anderson, con lo que pudimos conocer algo de lo que muy pronto comenzaría a llamarse "neomarxismo". Muchas de esas referencias teóricas están en mi tesis de licenciatura.

- Este es el tema de tu libro El estante vacío. Literatura y política en Cuba (2009), donde indagás la política editorial del Estado cubano y su prohibición de ciertas lecturas ¿De qué manera se producía la formación de un estudiante de filosofía en un contexto de este tipo, en el cual llegaban los libros a través de fragmentos en revistas o clandestinamente?

- Había un desfase en nuestra formación ya que no teníamos 
acceso directo a los libros de Foucault, de Habermas, de Marcuse o de Hobsbawm, puesto que no circulaban dentro de la isla. Era una formación muy a retazos, como en la Unión Soviética y todo el campo socialista. La filosofía occidental se leía a través de revistas, antologías o de libros que de pronto llegaban y pasaban de mano en mano. Los libros de Foucault, por ejemplo, no se editaban en Cuba, pero llegaba un ejemplar de ediciones Siglo $\mathrm{XXI}$ y circulaba promiscuamente entre nosotros. Ese, como te decía, fue el campo referencial de mi tesis de licenciatura que se presentó en el verano de 1990 en la Facultad de Filosofía e Historia de la Universidad de La Habana. Después en México me di cuenta que lo que yo intenté lo había hecho mucha gente, mucho mejor. En ese tiempo, por ejemplo, seguía de cerca a Marshall Berman y su libro Todo lo sólido se desvanece en el aire (1982). Pero tal vez la peculiaridad, en mi caso, es que mi tesis proponía una especie de hibridez entre la filosofía soviética neohegeliana y neokantiana, lliénkov y Orudzhev, y todos esos filósofos posmodernos, los alemanes, británicos y franceses, fundamentalmente. En mi tesis "Marx y la historia" se desarrollaba un argumento muy fuerte a favor de la historia y en contra de la metafísica, del carácter especulativo de la filosofía, que era muy común en todo el pensamiento posmoderno. Foucault era muy insistente en eso de pasar de la metafísica a la historia. Y eso tiene que ver, naturalmente, con mi decisión de seguir los estudios doctorales en historia.

-Antes de abordar esa etapa, una pregunta quedó pendiente para terminar de entender tu trayectoria inicial ¿cómo funcionaba el grupo de estudiantes que empezaron a tener críticas hacia el gobierno cubano a fines de los ochenta? ¿Tenían una organización interna y un nombre que referenciara sus anclajes colectivos?

- Esos años fueron de movimientos culturales muy interesantes en la juventud cubana, que han sido estudiados recientemente. Está la tesis de Velia Cecilia Bobes en El Colegio de México sobre esas experiencias culturales. Por ejemplo, en la plástica había un grupo muy activo que buscaba un tipo de intervención pública desde las artes. También existía un colectivo de creación que se llamaba "Arte Calle" y hacía happenings y performances en los parques de La Habana. Había otro proyecto que se llamaba "Hacer" que experimentaba con comunidades desde un punto de vista más antropológico, con los comités de defensa o las colonias agrarias. Se vivió una gran politización de la cultura en las artes y también en el teatro, la literatura y la filosofía. Hubo una experiencia que se llamó "Proyecto Paideia" con la que estuve vinculado. Era como un intento de difusión del pensamiento y la literatura de los años ochenta, al margen de las instituciones oficiales. En realidad, todas esas iniciativas estaban relacionadas con un forcejeo con las instituciones, entre las que se encontraban la Universidad y otros espacios del Ministerio de Educación o el Ministerio de Cultura.
En aquellos años esos forcejos eran una fricción todavía muy circunscrita al proyecto hegemónico del Estado cubano. Hasta fines de los ochenta y principios de los noventa, lo que se estaba buscando no era confrontar ese proyecto, sino más bien compensarlo o acompañarlo críticamente. Recién a mediados de los noventa se produce una delimitación de los espacios y buena parte de aquella cultura crítica de los ochenta se vuelve claramente disidente u opositora. Es el caso de los que ya vivíamos fuera de Cuba en ese tiempo, como Jesús Díaz y el grupo de Encuentro de la Cultura Cubana, o los que vivíamos aquí en Ciudad de México, como Eliseo Alberto y yo. Había una tensión en dos sentidos, ya que nosotros nos íbamos politizando, pero también el Estado cubano nos cambiaba el estatus migratorio, con lo que dejábamos de ser profesionales residentes en el exterior para ser exiliados.

- ¿Tu decisión de irte de Cuba a qué se debió? ¿Cómo fue tu experiencia personal en ese sentido y cuáles fueron los hechos políticos que a vos te interpelaron personalmente en esa etapa?

- Yo en realidad no me voy de Cuba con la idea de exiliarme, sino con el propósito de estudiar en el Colegio de México el doctorado en historia, en la generación de 1991-1995. Quien me recomendó para ese doctorado fue un historiador cubano de la economía de plantación azucarera esclavista, muy célebre, Manuel Moreno Fraginals. Él se había graduado en el Colegio de México en los años cuarenta y mantenía una comunicación muy fluida con algunos profesores que fueron después mis maestros, como Josefina Zoraida Vázquez, la directora de mi tesis doctoral. Pero hice el doctorado en el Colegio de México entre 1991 y 1995 viajando constantemente a Cuba. Tenía fricciones en cada viaje porque mi círculo seguía siendo el de mis compañeros de generación, que eran todos filósofos, historiadores, artistas y escritores con posiciones cada vez más críticas con respecto al sistema cubano, sobre todo a su política cultural y educativa. $Y$, claro, escribíamos en las mismas publicaciones, como El Caimán Barbudo, Albur, el suplemento Naranja Dulce y la revista Unión. Algunos llegamos a publicar en Casa de las Américas e incluso yo publiqué algo a principios de los noventa en la Gaceta de Cuba. En esas publicaciones se pueden encontrar las polémicas de nuestra generación con las generaciones previas y con quienes sostenían una línea más oficial con respecto al socialismo cubano, en los años que siguieron a la caída del Muro de Berlín y la desintegración de la URSS.

En nuestros grupos, la posición mayoritaria era que el sistema cubano debía abrirse. Es decir que Cuba, como parte del campo socialista y del bloque soviético, debía experimentar, a su manera, un proceso de reformas y de apertura informativa y cultural, como el que estaba teniendo lugar en todos aquellos países. Desde luego, esa no fue la posición del gobierno y creo que, muy hábilmente para sus propios fines, Fidel Castro se dio cuenta de que había que cerrar filas en contra de los procesos de cambio en 
Europa del Este. Nuestra generación se vio atrapada ahí en una tensión poderosísima que llevó a la confrontación ideológica y política a mediados de los años noventa.

\section{- ¿En ese momento se da el clivaje que muestra el pasaje del acompañamiento crítico a la oposición directa que nombrabas anteriormente?}

- Exacto, el pasaje a la oposición o a la disidencia. Aunque hay que hacer distinciones ya que es la oposición de una diáspora nueva que no se reconocía dentro del exilio histórico. Lo que hoy se conoce en los estudios culturales cubanos como "la diáspora de los noventa" eran todos aquellos artistas, escritores, cineastas y teatreros de los ochenta que nos desperdigamos por el mundo. Muchos vinimos a México y otros a España. Los que se iban a Estados Unidos trataban de ubicarse fundamentalmente en Nueva York y evitar Miami. Es un tipo de migración muy distinta a la histórica del anticomunismo y el anticastrismo de la Guerra Fría. Ahora, en medio de esa confrontación, se producen las respuestas más ideológicas del gobierno de Cuba. Una de las acusaciones mayores que nos hacían desde La Habana oficial era que todos nosotros, los que nos vinculamos a la revista Encuentro de la Cultura Cubana, éramos lo mismo que los viejos exiliados de Miami. Supuestamente el lenguaje cambiaba y las formas eran otras, pero al final, según ellos, se trataba de lo mismo. Lo que buscaba el discurso oficial era homogeneizarnos y asimilarnos al viejo exilio. Aunque hay que decirlo, en algunos casos, no tanto en mi generación, pero sí en generaciones mayores, se produjo una politización que acabó colocando a muchos de la diáspora de los noventa en posiciones parecidas a las del exilio tradicional de Miami.

—¿En qué momento ya no pudiste viajar más a Cuba en esa nueva etapa y cómo fue la formación de Encuentro de la Cultura Cubana? El primer número fue editado en 1996, aunque vos recién en el año 2000 sos codirector de la revista.

- Sí, a principios de los 2000 cuando muere Jesús Díaz. En realidad, la revista se lanza en 1996, pero desde el año 94 hubo reuniones previas en Madrid con escritores y artistas. La diáspora había sido impresionante, estamos hablando de cientos de artistas, escritores, académicos y cineastas que salimos entre 1989 y 1993-94. Como era tanta la emigración, rápidamente se produjeron sociabilidades y Encuentro de la Cultura Cubana fue justamente el resultado de eso. Fue la revista de aquella diáspora de los noventa. El último viaje que hice en condiciones normales a Cuba fue en diciembre de 1994, unos meses antes de que acabara la parte docente del programa doctoral. Más bien antes de que acabara la beca, ya que había terminado la parte docente justo en el 94, pero me quedaba la beca hasta 1995. A mí ya me habían ofrecido trabajo en el Instituto de Investigaciones Históricas de la UNAM y en 1996 en el CIDE. Justo en esos años, 95 y 96, asisto a varias reuniones del núcleo fundador de la revista Encuentro de la Cultura Cubana, especialmente con Jesús Díaz y con mi maestro Manuel Moreno Fraginals que también se había exiliado. La diáspora de los noventa era de todas las generaciones. Se iba desde un académico marxista consagrado de 74 o 75 años como el propio Moreno, que había sido amigo del Che, hasta escritores jovencitos de veintitantos años. En aquellas reuniones de Encuentro de la Cultura Cubana ya se vislumbraban los conflictos políticos más directos con el gobierno cubano. No diría que en todos los participantes, porque en realidad en esa revista publicaron muchísimos escritores, artistas, historiadores que vivían y residían en la isla. Pero la línea más dura de La Habana, la más ideológica, vio a Encuentro de la Cultura Cubana como un acto hostil, como una revista que desde fuera de Cuba se planteaba confrontar directamente al sistema. Para mí todo eso debe matizarse, pero en efecto ahí empiezan los problemas. En el año 97 o 98 nos cambiaron el pasaporte a Eliseo Alberto, a mí y a muchos más. Cuando te cambian el pasaporte quiere decir que pierdes el pasaporte ordinario y te dan uno consular, el cual requiere de un permiso especial, de una visa, para viajar a la isla. Durante mucho tiempo no pedí ese permiso. Sólo lo he hecho en dos ocasiones, una por cierto bastante reciente, que me negaron. Y en 2009, cuando murió mi padre, que pude viajar excepcionalmente. Me dieron un permiso humanitario para ingresar a la isla por cinco días. Ese es el único viaje que he hecho a mi país en 25 años.

- ¿Cómo transitaste familiarmente todo ese proceso porque parte de tu familia siguió en la isla? ¿Y qué implicancias tenía reconocerte o no como exiliado?

- Mi familia está muy politizada. Mi padre fue funcionario del Ministerio de Educación Superior, un hermano mío es Viceministro de Cultura y la generación más joven ya comienza a posicionarse en los debates políticos de la isla. En todos estos años ha habido momentos de mucha tensión, pero tal vez por el tipo de familia que somos, hemos podido sobrellevar las diferencias ideológicas y políticas manteniendo el afecto. Aunque a veces ha sido muy difícil, casi imposible, realmente. Te diría que el momento más difícil fueron los años de lo que en Cuba se llamó "La Batalla de Ideas", que encabezó Fidel Castro entre 1998 y 2003 - 2004. Hubo episodios realmente tristes, como el de aquella Feria del Libro de Guadalajara del año 2001 dedicada a Cuba, donde la delegación oficial hizo actos de repudio contra mis presentaciones. Me parece que ese fue el momento de mayor confrontación, cuando el Estado cubano decidió que mi condición era la de un enemigo. Todavía en muchas publicaciones oficiales se mantiene ese trato, aunque mi comunicación con el campo académico e intelectual de la isla es cada vez mayor.

Tú preguntabas por la condición de exiliado, ahí creo que hay que hacer una distinción. Te diría que la mayoría de nosotros, los grupos que vivíamos en Ciudad de México, Barcelona y Nueva York, donde estaban Eliseo Alberto, el propio Jesús Díaz, el crítico Iván 
De La Nuez o la socióloga de FLACSO Velia Cecilia Bobes, no nos asumíamos a nosotros mismos como exiliados, como sí lo hacían los de Miami. Nosotros más que nada nos veíamos como miembros de la diáspora de los años noventa. Aunque nuestra condición migratoria correspondía más propiamente a la de un exiliado y, como te decía antes, el discurso oficial nos asimilaba al viejo exilio de Miami.

- En tu primera etapa fuera de Cuba y sobre todo en tu participación en Encuentro de la Cultura Cubana ¿cuáles son las nuevas lecturas en tu formación político intelectual? $Y$ con relación a las diferencias con el exilio de Miami ¿en qué temas y discusiones hacían ustedes hincapié para que no los equipararan desde la isla a esos sectores?

- En términos de formación intelectual en los años noventa, para mí lo fundamental fue el contacto con la historiografía, especialmente con la nueva historia política de entonces, que estuvo muy concentrada en el debate sobre el nacionalismo. Fueron muy importantes en mi formación los estudios de Ernest Gellner, Anthony Smith y del propio Hobsbawm sobre los nacionalismos. También fue relevante la historiografía académica en general, que incluyó desde Francois Furet hasta Francois-Xavier Guerra y desde Gordon Wood hasta Bernard Bailyn. En el Colegio de México leí mucha historia económica e historia de las relaciones internacionales. Mi tesis de doctorado, Cuba mexicana. Historia de una anexión imposible (1999), es una especie de historia internacional, donde analizo la construcción de las políticas hacia Cuba en México durante todo el siglo XIX. Pero también traté de rehacer el proceso intelectual del imaginario sobre Cuba en la clase política mexicana, desde Lucas Alamán hasta Porfirio Díaz. Esa formación fue clave para mí y la utilicé para pensar algunos aspectos de la historia de Cuba en los siglos XIX y XX. Por otro lado, en los noventa y hasta la actualidad, sigo manteniendo vivo mi interés en el marxismo y el neomarxismo. Aunque tal vez mi propio trabajo académico se fue orientando más hacia la historia política y la historia intelectual.

Sobre tu pregunta de nuestra relación con el exilio tradicional, tal vez la clave de eso es nuestro origen. Nosotros no podíamos ser anticomunistas en el sentido de la derecha en la Guerra Fría, aglutinada como comunidad en Miami. Nuestra propia experiencia no encajaba en eso. En algunos casos se dio esa confluencia, pero creo que fueron procesos de mutación antropológica o psicológica que tenían que ver con personas que terminaron viviendo en Miami. El lugar donde tú vives es decisivo y en México ese tipo de mutaciones o metamorfosis no son tan fáciles, tampoco en Barcelona, Nueva York o en otros lugares de la emigración más reciente. Todos estos debates pueden verse en los primeros números de Encuentro de la Cultura Cubana y luego en mis propios libros sobre Cuba escritos a finales de los noventa, como Isla sin fin: contribución a la crítica sobre el nacionalismo cubano (1998) o El arte de la espera: notas al margen de la política cubana (1998). Pero el libro mío que más molestó en la isla se Llama José Martí: la invención de Cuba (2000). Es un trabajo caricaturizado por el discurso oficial. Todavía en una página llamada EcuRed aparece que yo, supuestamente, estaba llamando a olvidar a Martí, cuando lo que hice fue tratar de reconstruir sus ideas desde la perspectiva del republicanismo hispanoamericano, siguiendo la tesis de Pocock, Skinner, Viroli y otros autores. También estudiaba aspectos específicos de la obra de Martí como sus proyectos de libros no escritos, su discurso sobre el silencio, su conceptualización de la modernidad y su visión de Estados Unidos. Era absurdo que releyera toda la obra de Martí para concluir que había que olvidarlo.

\section{- En los noventa hay toda una revalorización de la figura de Martí en Cuba y tus primeros libros forman parte de esos de- bates en torno al discurso nacionalista de la isla.}

- Sí, mis libros entran en esa discusión. En realidad, el origen de muchas de esas polémicas tiene que ver con mis primeros ensayos publicados en Casa de las Américas y la Gaceta de Cuba. Es decir, en publicaciones de la isla donde discutía con intelectuales de las generaciones anteriores que se volvieron ideólogos del gobierno cubano en los noventa, como Cintio Vitier, Roberto Fernández Retamar, Eduardo Torres Cuevas y otros. Con todos tuve polémicas públicas muy respetuosas, pero ellos a su vez, como siempre pasa, tenían discípulos que no eran tan respetuosos. Si ellos me decían "has hecho una lectura equivocada", sus discípulos me trataban como un "neoanexionista" o un "contrarrevolucionario". Esos términos nunca los usó Cintio Vitier, por ejemplo, cuando discutía conmigo sobre Martí, Lezama o el nacionalismo revolucionario. Fernández Retamar venía, naturalmente, de una tradición más cercana a la nueva izquierda descolonizadora, pero también hacía coincidir su nacionalismo con el marxismo leninismo. Desde su ensayo Calibán $(1971 ; 1993)$ había una condescendencia tremenda hacia la ideología del socialismo real y el marxismo leninismo, algo que cuestionaba en mis libros. Creo que ahí está uno de los centros de aquellos debates: qué tanto se le concedía al marxismo-leninismo de corte soviético y qué tanto se volvía en un sustituto de esa ortodoxia desde el nacionalismo revolucionario.

En esos primeros libros me enfrenté al dilema de, por un lado, distinguir la tradición republicana de la liberal y, por otro, reconstruir con mayor fidelidad la propia tradición liberal cubana. Me parecía que se había dejado de lado la tradición de Francisco de Arango y Parreño, José Antonio Saco, Enrique José Varona y Jorge Mañach, con el énfasis en lo que llamaba la "teleología del nacionalismo cubano", que se reducía a unas cuantas figuras: Félix Varela, José Martí, Rubén Martínez Villena, Julio A. Mella, Antonio Guiteras y luego Fidel Castro. Se borraba toda una tradición liberal, en algunos casos reformista y en otros más claramente republicana. Todos esos libros míos buscaban rescatar el republicanismo de Martí, volver a estudiar el reformismo de Arango y 
de Saco, replantear el problema del positivismo con Enrique José Varona y distinguir el civismo de Mañach, que muchos ideólogos oficiales despreciaban. Vitier mismo creía que Varona era el rival de Martí, lo cual no es sostenible. Pero él tenía esa idea monárquica de Martí donde cualquier figura que le hiciera sombra al "apóstol" en el siglo XIX cubano debía ser vista con desconfianza. Creo que todas estas discusiones fueron muy manipuladas y no sólo por los ideólogos de la isla, también por sectores del exilio tradicional.

Me parece que Encuentro de la Cultura Cubana es una revista que da cuenta muy bien de todas aquellas preocupaciones. Por ejemplo, la preocupación por el canon nacional de las letras, quién está excluido, quién está adentro y cuáles son los escritores, pensadores o figuras de la tradición cubana subvaloradas, ya sea por su liberalismo o por su marxismo heterodoxo, como el caso de Walterio Carbonell. A mí siempre me llamó la atención que Fernández Retamar, quien trataba de asumir con mayor énfasis la descolonización, obviara a Walterio Carbonell, el marxista negro cubano más importante de los años cincuenta y sesenta. Tenía un pensamiento genuinamente panafricanista y muy conectado con las tesis de Frantz Fanon ¿Por qué lo obviaba? Porque Carbonell terminó, como todo el grupo de Pensamiento Crítico, marginado cuando el marxismo heterodoxo fue derrotado por la ortodoxia soviética en la lucha ideológica de los años sesenta y setenta en la isla.

- Para cerrar esta primera parte de tu trayectoria político intelectual, si tuvieras que hacer una retrospectiva del itinerario de Encuentro de la Cultura Cubana ¿cuáles serían las etapas más importantes del proyecto editorial y de tu trayectoria en él?

- La revista cerró en el 2009, pero yo había renunciado a la dirección tres años antes, así que el último período, desde el 2006 al 2009, no lo conozco tan bien. A mí me parece que hay que distinguir muy claramente entre la revista impresa, que fue la que codirigí desde el 2002 al 2006, y la página electrónica que se Llama Cuba Encuentro y originalmente se llamó Encuentro en la Red. Existe mucha confusión sobre eso, porque la página electrónica era editada por la misma asociación que auspiciaba la edición de la revista desde Madrid. Mi función sólo tuvo que ver con la revista impresa. Los primeros años que la dirigí todavía el gran objetivo era mantener una red de colaboradores bien repartidos entre la isla y la diáspora. La idea era enfocarse muy fuertemente en los vacíos, las exclusiones y los solapamientos de la tradición cultural cubana para tratar de reparar olvidos. Fíjate que la revista en cada número hacía un homenaje a una figura central de la cultura cubana que considerábamos que estaba subvalorada dentro o fuera de la isla, como Tomás Gutiérrez Alea, Fina García Marruz, Abelardo Estorino, Antón Arrufat, entre otros. Hicimos dossiers sobre la guerra del 98, el racismo en Cuba, el éxodo del Mariel, los balseros del año 94, ciertos hitos de la historia contemporánea de Cuba que eran muy incómodos de tratar desde el discurso oficial. El discurso oficial dentro y fuera porque el discurso oficial anticomunista tampoco se interesaba en esos temas.

Creo que la propia confrontación se vuelve álgida en el período de "La Batalla de Ideas", como lo denominó Fidel Castro, el cual coincide con el gobierno de George W. Bush y el reforzamiento del embargo. Cuando la revista empezó era la época de la Ley Torricelli en 1992 y la Ley Helms-Burton en 1996. En esos primeros números de la publicación cada uno de nosotros como articulista publicó editoriales, dentro o fuera de la revista, donde nos pronunciábamos en contra de las sanciones de Estados Unidos a Cuba. Tú me preguntabas antes cuál era el punto clave de distinción con el exilio de Miami y te diría que siempre nuestra diáspora fue, mayoritariamente, contraria a la política de Estados Unidos contra Cuba y en mis libros siempre hay alguna nota de rechazo al embargo comercial o a la Ley Helms-Burton. Ahora, a mediados de los 2000, aunque yo mismo como articulista en El País o en otros espacios me oponía siempre a Bush, la confrontación fue contaminando el propio discurso de la revista. Además, existe otra razón de peso en esos últimos años: el gobierno cubano logró desarticular la importante comunidad dentro de la isla que sostenía la revista. Así lograron estigmatizarnos a todos, pero especialmente a Jesús Díaz, a Raúl Rivero y a mí, lo cual nos restó apoyo dentro de la isla.

\section{Segunda parte: política e intelectuales en los sesenta latinoamericanos}

- Ya sea en Tumbas sin sosiego (2006) o en otros libros de tu autoría donde abordás distintas temáticas, como Las repúblicas del aire. Utopía y desencanto en la revolución de Hispanoamérica (2009), El estante vacío. Literatura y política en Cuba (2009), La polis literaria. El boom, la revolución y otras polémicas de la Guerra Fría (2018), existe una preocupación por entender las relaciones entre política e intelectuales, especialmente de los vinculados a las fuerzas de izquierda. Si nos situamos en los años sesenta y setenta en América Latina, ese nudo fue una problemática clave vinculada a la Revolución Cubana y a la Guerra Fría. En Argentina, por ejemplo, trabajos clásicos como los de Oscar Terán (1991) y Beatriz Sarlo (2001), sostienen que en ese marco la politización y radicalización de los intelectuales llevó a la disolución de la cuestión intelectual e incluso al pasaje a la lucha armada de varios actores que podrían incluirse bajo ese rótulo. Silvia Sigal (1991) matiza un poco esta hipótesis al señalar que detrás de los discursos radicales y del antiintelectualismo en verdad había una fuerte operación intelectual. En tu caso, ¿cómo creés que deben entenderse las relaciones entre política e intelectuales en los años sesenta y setenta en América Latina? A su vez, ¿cuáles 
son las similitudes y diferencias que encontrás en las formas en que se tramitaron esos vínculos al interior de la isla y fuera de ella, ya sea en países como México, Argentina y Chile, por tomar algunos ejemplos relevantes?

- Ahora mismo ese es un campo en proceso de redefinición en la historia intelectual y política latinoamericana contemporánea. En aquellos estudios que hice lo que más me interesaba era explorar la manera en que Cuba intervenía en los distintos posicionamientos dentro del campo intelectual latinoamericano. Sin embargo, cuando uno va un poco más a fondo y trata de interrelacionar esa historia intelectual con la historia política, encuentra que existe un flanco muy rico de debates entre las opciones de lucha de la izquierda latinoamericana en los años sesenta y setenta, las cuales tuvieron un componente intelectual decisivo, porque hacer la revolución también era pensar teóricamente en las vías de lucha revolucionaria. Entonces, si recorres las distintas formas de entender la lucha armada en todas las opciones guerrilleras hasta el proyecto pacífico y electoral de la Unidad Popular y Salvador Allende en Chile, encuentras que esos posicionamientos siempre estuvieron acompañados de fuertes debates intelectuales. En realidad, es muy difícil concluir que la lucha de posiciones en torno a Cuba y en general de la izquierda, contribuyó a una descapitalización intelectual de aquellos movimientos.

Estas son reflexiones un poco más recientes en mi producción. Me parece que mi contribución en aquellos libros tiene más que ver con trabajos como los de Claudia Gilman (2003) e Idalia Morejón (2010), ya que, en buena medida, se trataba de un pretexto para recolocar a Cuba en esa heterogeneidad ideológica y política. Una de las motivaciones de esos libros era tratar de confrontar el encapsulamiento o la homogeneización de posiciones que se atribuyen tradicionalmente al respaldo a la Revolución Cubana. Se pierden muchos matices críticos en esos enfoques planos, sobre todo en la visión oficial cubana. Se da por sentado que todo apoyo a la Revolución Cubana o al socialismo implica la asimilación acrítica del conjunto institucional o del repertorio discursivo producido por los aparatos de legitimación del gobierno cubano. Para empezar eso no es así desde los propios actores del socialismo cubano en los sesenta. Por ejemplo, en el Che Guevara tenemos claramente una idea de revolución y una idea del socialismo muy diferentes a las del grupo pro soviético del antiguo Partido Socialista Popular, donde figuraban Carlos Rafael Rodríguez, Mirta Aguirre y Juan Marinello. Lo mismo podemos pensar a propósito de la revista Pensamiento Crítico, donde se manejaron distintas ideas de la revolución y de las guerrillas.

- Tus trabajos recientes indagan los distintos significados que se otorgaron a la lucha revolucionaria en revistas cubanas importantes como Lunes de Revolución, Pensamiento Crítico y Cuba Socialista (2020).

- Sí, estoy trabajando en eso justo ahora. Estos debates hay que llevarlos, como hacen Vera Carnovale (2011), Aldo Marchesi (2019) o Eugenia Palieraki (2014), a la micro historia de los movimientos armados o de los movimientos políticos de la izquierda en general. No toda la izquierda estuvo por la vía armada en los años sesenta y setenta y el campo de las teorías de la revolución fue muy complejo. Si nos detenemos nada más que en un punto de aquellos debates, como la discusión sobre la teoría del foco guerrillero, nos encontramos con todo tipo de posiciones. Desde la de Carlos Marighella que defendía la guerrilla urbana en contra de las propias tesis de Régis Debray y el Che, hasta a veces el mismo Fidel Castro quien llegó a decir que las guerrillas no eran posibles en países como Uruguay, Argentina y Brasil. Claro, para el Che sí podía haberlas, pero igual pensaba que había que organizarlas priorizando el movimiento armado del campo. O las tesis de Ángel Bengochea y de Rubén Navillait. También Abraham Guillén es un caso muy interesante que estudia Aldo Marchesi en su libro (2019). O Vania Bambirra que es un caso fascinante porque polemizó directamente con Régis Debray con un seudónimo, Cléa Silva, en un artículo que manda a Monthly Review. Y me parece que ella también, con seudónimo, está detrás de algunas colaboraciones en Pensamiento Crítico. En esta publicación existe una riqueza enorme. Pensamiento Crítico era una revista hecha por intelectuales guevaristas que entendían a Régis Debray, pero no podían evitar involucrar visiones de la teoría revolucionaria y de la práctica revolucionaria diferentes a las que se defendían en la misma revista. Eso lo hacían sin coincidir nunca con el bloque pro soviético. De manera que estamos en una especie de campo de batalla de la teoría con muchos flancos que hay que rescatar mejor en futuros trabajos.

- Para contribuir a ese objetivo un punto importante es el de las teorías y conceptos que los investigadores ponen en jugo en sus análisis. En muchos estudios, se utilizó bastante a Pierre Bourdieu para pensar el tema de los intelectuales y sus luchas de poder. En tu caso ¿qué caminos teóricos-metodológicos recomendás para abordar la relación entre política e intelectuales en esos años?

- Para mí también fue muy útil Bourdieu en una época, en especial sus conceptos de campo intelectual y reglas del arte. Por ejemplo, me servían para estudiar los vaivenes del canon nacional de las letras o para indagar las fricciones entre el campo intelectual, las instituciones políticas y las élites del poder, en términos de autonomía o compromiso. Para todas esas cuestiones sigue siendo muy importante Bourdieu. Ahora, si nos colocamos en esta perspectiva de avanzar en un mapa mucho más complejo de las izquierdas latinoamericanas en los años sesenta y setenta, debemos movernos con mayor flexibilidad desde un punto de vista analítico y metodológico. Creo que es fundamental entender que esas décadas fueron un momento en que la teoría y la práctica de la revolución no estuvieron disociadas. Decir "hacer la revolución" era también "pensar la revolución". Por eso necesita- 
mos aprender mucho de la propia historia política y tratar de reconstruir con mayor precisión toda esa gama de organizaciones. Para empezar, no tenemos el mapa completo de la izquierda armada en América Latina. Hay muy buenos estudios sobre el Ejército Revolucionario del Pueblo (ERP) argentino de Mario Roberto Santucho, sobre el Movimiento de Izquierda Revolucionaria (MIR) chileno de Miguel Enríquez, sobre el Ejército de Liberación Nacional (ELN) boliviano, sobre los Tupamaros de Uruguay, los Montoneros en Argentina e incluso de experiencias trasnacionales como la Junta de Coordinación Revolucionaria (JCR) que nucleaba a varios de esos grupos. Pero todavía no tenemos la sociología histórica de aquella izquierda tan diversa y mucho menos hemos reconstruido la amplia gama de polémicas teóricas en torno al concepto de revolución en los años sesenta y setenta. A veces tengo la impresión de que el debate metodológico se adelanta al propio trabajo empírico. Nos falta todavía mucho trabajo empírico para llegar ahí, pero coincido en que se requieren nuevas claves metodológicas para pensar esas décadas.

\section{Tercera parte: los usos de la nueva izquierda y sus desafíos}

\begin{abstract}
- En Traductores de utopía. La revolución cubana y la nueva izquierda de Nueva York (2016) analizás las distintas maneras en que las experiencias políticas e intelectuales de la nueva izquierda neoyorkina se posicionaron ante $\mathrm{Cuba}$, tomando distintos casos que van desde la Beat Generation hasta los Black Panthers. La tesis es que Nueva York y otras capitales culturales - como México y Buenos Aires- ofrecieron el debate teórico y el choque público de ideas que faltó a la Revolución desde 1961, a raíz del control y la centralización del Estado. Lo interesante es que el libro propone entender a la gesta cubana como un fenómeno trasnacional que puso en juego distintas políticas de traducción de la utopía en la nueva izquierda de Estados Unidos y América Latina. Desde este trabajo y tus discusiones posteriores ¿cuáles son las principales potencialidades y limitaciones que vislumbrás en el uso analítico de la categoría nueva izquierda, teniendo en cuenta que, si bien existe un marco global, las diferencias nacionales operan y pueden ser muy determinantes?
\end{abstract}

- En realidad un déficit de mi libro es que no hay una exploración conceptual en torno a la idea de nueva izquierda. Lo que me interesaba era avanzar un poco más empíricamente en el mapa de todos esos movimientos diversos en la Nueva York de los años sesenta y en la manera en que se relacionaron con Cuba. En principio, te diría que me sigue pareciendo pertinente el concepto de nueva izquierda. En el libro menciono, de pasada, dos definiciones del concepto. Una de Charles Wright Mills que es muy conocida. Su famosa carta a la New Left Review sobre la nueva izquierda. La otra no es tan conocida y está en el ensayo de 1959 de E. P. Thompson sobre la nueva izquierda. Los dos escritos están en diálogo porque había una correspondencia entre ambos. Cuando Wright Mills escribe para contribuir al relanzamiento de la The New Left Review está poniendo en claro su conversación con Thompson. Ahora, si uno lee con cuidado los dos textos, observa que existe una gran diferencia entre ambos y la clave está en cómo entiende cada uno la Guerra Fría.

Para Wright Mills la nueva izquierda implicaba un abandono de la vieja izquierda. Una vieja izquierda que entendía en el sentido de la izquierda soviética de los Partidos Comunistas, el viejo Comintern, la estrategia del deshielo y la desestalinización de Kruschev. Todo eso englobaba a la vieja izquierda, como el comunismo hegemónico que intervenía en Hungría en 1956, defendía la economía centralizada, el socialismo burocrático, el partido único y la ideología marxista leninista. Pero para Wright Mills la nueva izquierda necesariamente era una izquierda tercermundista, es decir descolonizadora. Él pensaba que la Guerra Fría iba dejando de tener sentido en la medida en que el mundo giraba en torno al conflicto entre el primer mundo y el tercer mundo. El segundo mundo iba quedando fuera como referente porque justamente era el patrimonio de la vieja izquierda y el socialismo real. En cambio, en el tercer mundo surgía otra manera de entender y de practicar la revolución que era clave y estaba asociada a la nueva izquierda.

En cambio, para E. P Thompson eso no es tan importante, menciona de pasada a la descolonización, el racismo y Vietnam. Para él lo relevante es desafiar la ortodoxia marxista leninista soviética por medio de otro tipo de lucha e incluso llega a decir: "ya para la nueva izquierda no es importante la toma del poder". Imagínate, al Che Guevara, una figura emblemática de la nueva izquierda, debió sonarle como un sinsentido lo que decía Thompson. Sin embargo, es muy interesante rescatar aquellos ensayos de Thompson sobre la revolución y la nueva izquierda porque partían de un empeño de superación del concepto de Guerra Fría, como sistema bipolar, compartido por Occidente y la URSS, que hace mucho sentido en el siglo XXI.

En el marco de este tipo de discusiones, creo que sí tiene mucha pertinencia el concepto de nueva izquierda porque en todos los actores que podemos identificar, desde el Che Guevara, Frantz Fanon o Angela Davis, es fundamental la diferenciación con la vieja izquierda. Este es un aspecto a veces subvalorado a conveniencia de sectores que siguen existiendo, los cuales quieren asimilar la nueva izquierda a la vieja porque ésta sigue siendo muy poderosa. El enclave estalinista o del socialismo real dentro de la izquierda latinoamericana continúa con mucho poder y lo vemos claramente en Cuba. En la isla gobierna un partido que se llama Partido Comunista de Cuba y su ideología, formulada constitucionalmente, es el marxismo leninismo. Entonces se producen estos desdibujamientos o distorsiones deliberadas que impiden ver el proceso y los debates más en detalle. Por ejemplo, si vamos al fondo de las controversias sobre el foco guerrillero, nos encon- 
tramos con la discusión de cuáles son los sujetos revolucionarios y las clases que deben ser convocadas en la lucha, lo que lleva a la cuestión de cómo se piensa el campesinado o la pequeña burguesía. El gran debate entre Régis Debray, Fernando Henrique Cardoso y Vania Bambirra incluye todos esos temas. Ahora, si admites a las clases medias y te mueves a un formato de lucha que no necesariamente pasa por la lucha armada, sino que incluye la lucha electoral, como llega a decir Cardoso a principios de los setenta en The New Left Review, entonces tienes que pensar de otra manera conceptos como capitalismo, desarrollo y pequeña burguesía. Todo este mundo tan heterogéneo de discusión está ligado a algo que podemos definir como nueva izquierda y lo veo realmente muy útil.

Otra pregunta más complicada es cuándo deja de ser pertinente el concepto. Me parece que los orígenes del concepto sí están bastante anclados en el año 1959 y no necesariamente por la Revolución Cubana. La discusión entre Wright Mills y Thompson es de ese año y en ella no hay ninguna alusión a Cuba, eso lo menciono en mi libro. Recién un año después es que aparece el libro de Wright Mills sobre Cuba, pero en el momento que escribió esa carta a The New Left Review no menciona a Cuba, entre otras cosas, porque para él lo importante en esa etapa era tratar de plantear la diferencia con la vieja izquierda pro soviética. Él acababa de viajar a la URRS en ese momento. Además, Wright Mills escapa a una tentación en la que cae Thompson, que es la de limitar la nueva izquierda a Occidente. En realidad, Wright Mills dice que si existe algo como la nueva izquierda occidental es para dar algunas respuestas a lo que él llama el "bloque de países hambrientos del mundo", que son, justamente, las naciones del Tercer Mundo. Por eso, le termina dando tanta importancia al tema de la descolonización y, finalmente, a la Revolución Cubana.

- Teniendo en cuenta que tu trabajo cruza bibliografía estadounidense con trabajos de Latinoamérica ¿cuáles son los puntos en común y las diferencias que visualizás en los estudios socio-históricos más importantes sobre la nueva izquierda en Estados Unidos y en América Latina? Y, por otra parte, en relación con el tema vieja-nueva izquierda existen trabajos como los de la uruguaya Vania Markarian (2016) que recuperan esa tensión, pero a la vez sostienen que no hay que perder de vista que la Juventud Comunista también fue parte de los cambios culturales de los años sesenta y setenta. Por eso, proponen entender a la izquierda como un campo de colocaciones múltiples, donde se reposicionan tanto "viejos" como "nuevos" actores.

- Entro por esta última acotación. Evidentemente la Revolución Cubana y su impacto en América Latina contribuyeron a un cambio dentro de los Partidos Comunistas y las Juventudes Comunistas. Una vez que un Partido Comunista y una Juventud Comunista, por ejemplo, optaron por un modelo de guerrilla rural o de guerrilla urbana, terminaron asimilando las ideas del Che. Como pasaba en algunos grupos como los de Enríquez, de Santucho, los Tupamaros o los Montoneros. Ellos estaban practicando y pensando una revolución no diseñada y diferente al asalto del Palacio de Invierno por un Partido Comunista. Todos esos conceptos del leninismo tradicional estaban siendo revisados. El mismo Régis Debray trata de salvar la distancia diciendo que el leninismo latinoamericano es un leninismo práctico, pero realmente existió una gran desestabilización de valores y prácticas en todo ese proceso de los años sesenta y setenta. Por supuesto que no estoy diciendo que los Partidos Comunistas y las Juventudes Comunistas desaparecieron como actores; pero me parece que se fueron transformando por la propia dinámica de la lucha armada. Creo que incluso los propios soviéticos fueron acomodándose a ese cambio en los años setenta y ochenta, muy lentamente y en buena medida por la presión de Cuba. Porque Cuba ejerce, dentro del bloque soviético, la mayor presión dentro del horizonte de la nueva izquierda. China tal vez un poco al principio de los años sesenta, cuando era un referente muy fuerte para algunos de los panafricanistas, como Raymond F. Williams, y para algunos países de la descolonización norafricana. Pero el país que mantuvo la mayor presión dentro del bloque soviético entre los años sesenta y setenta, en el sentido de apertura a las lógicas de la nueva izquierda, fue Cuba.

En relación con los usos del concepto de nueva izquierda en Estados Unidos y América Latina lo que veo muy saludable en ambos casos es una nueva historiografía que complejiza la noción de Guerra Fría. Van por el lado globalizador de la Guerra Fría, pero también por el camino muy fecundo de trabajar en clave transnacional las izquierdas, como han hecho historiadores como Tanya Harmer (2011), Renata Keller (2015), Patrick Iber (2015) y Eric Zolov (2020). Un defecto de mis propios trabajos es que pueden volverse muy cubano céntricos o habano céntricos, en el sentido de que muchas veces trato de explorar el impacto de los debates que provoca Cuba. El enfoque de la conexión con Cuba da cuenta de una dosis importante de la lucha política de la izquierda en los años sesenta y setenta, pero no todo pasa por ahí. La dinámica transnacional genera sus propias lógicas autónomas o relativamente autónomas en distintos contextos. Por ejemplo, para el caso chileno es clarísimo. La propia evolución de la Unidad Popular, como ha estudiado Marcelo Casals (2010), tiene momentos de bastante desconexión con Cuba, aunque la retórica siempre busca insistir en la alianza entre Fidel y Allende. Dentro de la solidaridad hay tensiones internas muy fuertes. Ahí uno ve claramente el margen de relativa autonomía que se genera entre diversos sectores de la izquierda latinoamericana y comprueba, a la vez, que hay lógicas de los propios países que son más relevantes que otras en el marco de la dinámica trasnacional. 
Referencias bibliográficas

Berman, Marshall, Todo lo sólido se desvanece en el aire, España, Siglo XXI, 2004 [1982].

Carnovale, Vera, Los combatientes. Historia del PRT-ERP, Buenos Aires, Siglo xxi, 2011.

Casals, Mario, El alba de una revolución: La izquierda y la construcción estratégica de la "vía chilena al socialismo". 19561970, Santiago de Chile, LOM Ediciones, 2010.

Fernández Retamar, Roberto, Calibán, Buenos Aires, CLACSO, 2004 [1971, con Postdata 1993].

Gilman, Claudia, Entre la pluma y el fusil. Debates y dilemas del escritor revolucionario en América Latina, Buenos Aires, Siglo XXI, 2003

Harmer, Tanya, Allende's Chile and the Inter-American Cold War, Chapel Hill, University of North Carolina Press, 2011.

Iber, Patrick, Neither peace nor freedom: the cultural Cold War in Latin America, Cambridge, Harvard University Press, 2015.

Keller, Renata, Mexico's Cold War: Cuba, the United States, and the Legacy of the Mexican Revolution, New York, Cambridge University Press, 2015

Marchesi, Aldo, Hacer la revolución: guerrillas latinoamericanas de los 60 a la caída del muro, Buenos Aires, Siglo xxi, 2019.

Markarian, Vania, Uruguay 1968: student activism from global counterculture to Molotov cocktails, Berkeley, University of California Press, 2016.

Morejón, Idalia, Política y polémica en América Latina. Las revistas Casa de las Américas y Mundo Nuevo, México, Ediciones de Educación y Cultura, 2010.

Palieraki, Eugenia, ¡La Revolución ya viene! El MIR chileno en los años sesenta, Santiago de Chile, LOM Ediciones, 2014.

Rojas, Rafael, El arte de la espera: notas al margen de la política cubana, Madrid, Editorial Colibrí, 1998.

Isla sin fin: contribución a la crítica sobre el nacionalismo cubano, Miami, Universal, 1998.

Cuba mexicana. Historia de una anexión imposible, México, Secretaria de Relaciones Exteriores, 2002 [1999].
José Martí: La Invención de Cuba, Madrid, Editorial Colibrí, 2000

Utopía y desencanto en la revolución de Hispanoamérica, México, Taurus, 2009.

Tumbas sin sosiego. Revolución, disidencia y exilio del intelectual cubano, Barcelona, Anagrama, 2006.

El estante vacío: literatura y política en Cuba, Barcelona, Anagrama, 2009

-La Revolución cubana y la nueva izquierda de Nueva York, México, Fondo de Cultura Económica, 2016

-La polis literaria: El boom, la Revolución y otras polémicas de la Guerra Fría, México, Taurus, 2018.

Sarlo, Beatriz, La batalla de las ideas, Buenos Aires, Ariel, 2001.

Sigal, Silvia, Intelectuales y poder en la década del sesenta, Buenos Aires, Puntosur, 1991.

Terán, Oscar, Nuestros años sesentas, Buenos Aires, Puntosur, 1991.

Zolov, Eric, The last good neighbor: Mexico in the Global Sixties, Durham, n.c., Duke University Press, 2020. 